\title{
Spray-dried powders enhance vaginal siRNA delivery by potentially modulating the mucus molecular sieve structure
}

This article was published in the following Dove Press journal:

International Journal of Nanomedicine

26 August 2015

Number of times this article has been viewed

\author{
$\mathrm{Na} \mathrm{Wu}{ }^{1,2, *}$ \\ Xinxin Zhang ${ }^{2, *}$ \\ Feifei $\mathrm{Li}^{2}$ \\ Tao Zhang ${ }^{2}$ \\ Yong Gan ${ }^{2}$ \\ Juan $\mathrm{Li}^{\prime}$
}

'School of Pharmacy, China Pharmaceutical University, Nanjing, People's Republic of China; ${ }^{2}$ Shanghai Institute of Materia Medica, Chinese Academy of Sciences, Shanghai,

People's Republic of China

*These authors contributed equally to this work
Correspondence: Yong Gan Shanghai Institute of Materia Medica, Chinese Academy of Sciences, 50I Haike Road, Shanghai 201203, People's Republic of China

Tel +862 2I $2023 \quad 1000$ ext I424

Fax +86 2I 20231000 ext I425

Email simm2122@vip.sina.com

Juan $\mathrm{Li}$

School of Pharmacy, China

Pharmaceutical University,

24 Tongjiaxiang, Nanjing 210009 ,

People's Republic of China

Tel $+86258327 \quad 287$

Fax $+86258327 \quad 1766$

Email lijuancpu@163.com
Abstract: Vaginal small interfering RNA (siRNA) delivery provides a promising strategy for the prevention and treatment of vaginal diseases. However, the densely cross-linked mucus layer on the vaginal wall severely restricts nanoparticle-mediated siRNA delivery to the vaginal epithelium. In order to overcome this barrier and enhance vaginal mucus penetration, we prepared spray-dried powders containing siRNA-loaded nanoparticles. Powders with Pluronic F127 (F127), hydroxypropyl methyl cellulose (HPMC), and mannitol as carriers were obtained using an ultrasound-assisted spray-drying technique. Highly dispersed dry powders with diameters of 5-15 $\mu \mathrm{m}$ were produced. These powders showed effective siRNA protection and sustained release. The mucus-penetrating properties of the powders differed depending on their compositions. They exhibited different potential of opening mesh size of molecular sieve in simulated vaginal mucus system. A powder formulation with $0.6 \% \mathrm{~F} 127$ and $0.1 \%$ HPMC produced the maximum increase in the pore size of the model gel used to simulate vaginal mucus by rapidly extracting water from the gel and interacting with the gel; the resulting modulation of the molecular sieve effect achieved a 17.8-fold improvement of siRNA delivery in vaginal tract and effective siRNA delivery to the epithelium. This study suggests that powder formulations with optimized compositions have the potential to alter the steric barrier posed by mucus and hold promise for effective vaginal siRNA delivery.

Keywords: siRNA delivery, vaginal administration, spray-dried powders, mucus penetration, molecular sieve effect

\section{Introduction}

Vaginal delivery of small interfering RNA (siRNA) has been explored and shown to be a promising strategy for the treatment of vaginal viral infections and cervical cancer. ${ }^{1-3}$ Vaginal route has advantages over other routes such as site-specific delivery and circumvention of first-pass hepatic clearance. The hypotoxicity and low drug dose makes the vagina an excellent site for siRNA delivery to target viral genes or host genes. Nanoparticle-based gene delivery systems, such as positively charged liposomes, ${ }^{4}$ lipid-like molecules, ${ }^{5,6}$ and polymer nanoparticles ${ }^{7,8}$ have been evaluated in vaginal siRNA delivery because they show sustained release behavior and cellular targeting properties. Intravaginal administration with biodegradable poly (lactic-coglycolic acid) nanoparticles encapsulating siRNA showed efficient epithelial uptake and sustained gene silencing, ${ }^{7}$ improving survival of the mice after herpes simplex virus 2 infection. ${ }^{8}$ However, delivery of siRNA to the vaginal epithelium has been significantly impeded by the mucus layer covering the vaginal wall. ${ }^{9}$ Densely crosslinked mucin fibers with a woven mesh-like structure ${ }^{10}$ function as a molecular sieve; this restricts foreign particles that fail to fit through the mesh pores. The interactions 
of vaginal mucin with carrier systems, determined by their surface charge and chemistry, ${ }^{11,12}$ will decrease the motility of nanoparticles in mucus. These trapped siRNA-loaded nanoparticles are then subject to rapid elimination by mucus clearance mechanisms. ${ }^{13,14}$

Polymer gels are widely used as depots of nanoparticles for topical drug delivery ${ }^{15}$ due to their safety and potential to release drugs in a controlled manner. ${ }^{16} \mathrm{Carbopol}^{\circledR}$, poloxamer, and polyvinylpyrrolidone are commonly employed polymers in the preparation of gels. Mucoadhesive and environmentally sensitive gels have received considerable attention. Pavelic et $\mathrm{al}^{17}$ adopted mucoadhesive polyacrylate gel as a liposome vaginal delivery system to facilitate sustained drug release. Carbopols are anionic polymers that undergo rapid gelation when the solution $\mathrm{pH}$ changes, improving drug retention at the treatment site. ${ }^{18}$ However, a number of challenges confront the application of gels as the depots of nanoparticles for drug and gene delivery to mucosal tissues due to the physiological removal mechanisms. The conventional nanoparticles are not readily transported through the mucus barrier and are rapidly eliminated via mucociliary clearance, ${ }^{19,20}$ which dramatically reduces the efficacy of vaginal siRNA delivery. Discomfort and discharge of the gels also limits their use in vaginal administration. Alternative strategies are therefore required to overcome these limitations.

Currently, spray-dried powders are receiving a great deal of interest as transmucosal delivery systems. Powder formulations have greater chemical and microbiological stability, ease of administration, and can produce higher local drug concentrations at the treatment site, giving them an advantage over solution or suspension formulations. ${ }^{21}$ In addition, the high dispersion and rapid dissolution of the powders contributes to an extended and intimate contact with the mucosa; this consequently improves the drug residence time on the mucosal surface, offering the potential for the enhancement of vaginal siRNA delivery.

In this study, we designed four formulations containing mannitol and different levels of Pluronic F127 (F127) and hydroxypropyl methyl cellulose (HPMC), commonly used materials for topical mucosal administration. These blended materials were mixed with siRNA-loaded nanoparticles and spray-dried for vaginal administration. We investigated the siRNA protection capability of these powders and their siRNA release profiles. The performances of these powders and their corresponding solutions in vaginal siRNA delivery were evaluated. The structure and the rheological properties of a model gel representing vaginal mucus were also investigated before and after the addition of the powders or solutions.

\section{Materials and methods Materials}

Chitosan (MW $100 \mathrm{kDa}$; approximately 90\% deacetylated) was obtained from Golden-Shell Biochemical Co. Ltd. (Zhejiang, People's Republic of China). Egg lecithin (Lipoid E80) was obtained from Lipoid GmbH (Ludwigshafen, Germany). Pluronic F127 was a kind gift from BASF (Ludwigshafen, Germany). HPMC and hydroxyethyl cellulose (HEC) were purchased from Colorcon Co. Ltd. (Shanghai, People's Republic of China) and Ashland-Aqualon Inc. (Wilmington, DE, USA), respectively. Negative control siRNA and Cy5-labeled siRNA (Cy5-siRNA) were purchased from Shanghai GenePharma Co. Ltd. (Shanghai, People's Republic of China) and Biomics Biotechnologies Co. Ltd. (Jiangsu, People's Republic of China), respectively. All other chemicals and solvents were of analytical reagent grade.

\section{Preparation of nanoparticle-loaded spray-dried powders}

Chitosan nanoparticles (CS-NPs) were prepared using the ionotropic gelation method first described by Calvo et al. ${ }^{22}$ Briefly, tripolyphosphate sodium aqueous solution ( $2 \mathrm{mg} / \mathrm{mL}$ ) was added dropwise to a chitosan solution ( $2 \mathrm{mg} / \mathrm{mL}$ in $1 \%$ acetic acid) at 1,000 rpm (IKA PET basic; IKA, Staufen, Germany). Spontaneously formed CS-NPs were then concentrated by centrifugation (Tomos 2-16A; Tomos USA, Greenville, SC, USA) at $13,000 \times g$ for 30 minutes. After discarding the supernatant, the CS-NPs were reconstituted in distilled water for further studies. siRNA-loaded CS-NPs (CS-siRNA) were prepared by adding siRNA solution to the CS-NP suspension at a mass ratio of 1:100 while stirring.

CS-NPs coated with Lipoid E80 (E80/CS-NPs) were prepared by hydrating a dried lipid film with the suspension of CS-NPs. Briefly, E80 and cholesterol, at a mass ratio of 10:1, were dissolved in chloroform. The organic phase was removed at $40^{\circ} \mathrm{C}$ in a rotary evaporator (IKA RV 10 digital; IKA) to obtain a homogeneous thin lipid film, which was then hydrated with the CS-NP suspension (lipids: CS-NPs = $8: 1, \mathrm{w} / \mathrm{w}$ ) at $45^{\circ} \mathrm{C}$ for 30 minutes. The solution was extruded several times through polycarbonate membranes $(0.2 \mu \mathrm{m}$ pore diameter; Whatman Inc., UK) using Emulsi Flex-C5 (Avestin Inc., Ottawa, ON, Canada) to obtain E80/CS-NPs. E80/CS-siRNA was prepared by hydrating the dried lipid film with the CS-siRNA suspension. 
Dry powders containing E80/CS-NPs (or E80/CS-siRNA) were prepared using the high-frequency ultrasonic spray-drying technique. The construction of the powdered siRNA delivery system is shown in Figure S1. Aqueous solutions of the indicated formulations (Table 1) were supplied to the spray nozzle (Sono-Tek Corporation, Milton, NY, USA). The liquids were atomized into fine mists by highfrequency sound waves $(100 \mathrm{kHz})$. The feed rate was $1 \mathrm{~mL} /$ min, and the inlet and outlet temperatures were $120^{\circ} \mathrm{C} \pm 2^{\circ} \mathrm{C}$ and $65^{\circ} \mathrm{C} \pm 2^{\circ} \mathrm{C}$, respectively. The resulting powders were collected and stored at room temperature until use.

\section{Characterization of powders}

The viscosities of the mixed solutions of E80/CS-NPs and the range of dry powder carriers (Table 1) were measured using a LVDV-III rheometer (Brookfield, Middleboro, MA, USA) at $100 \mathrm{rpm}$ with a small-sample adapter (SSA 18/13RPY) at room temperature.

The size distribution of each dry powder was determined while spraying, using a laser particle sizer (DP-02; OMEC UK, Leeds, UK). The particle sizes of the nanoparticles reconstituted from the powders in pure water were measured by dynamic light scattering (Zetasizer Nano-ZS; Malvern Instruments, Malvern, UK) at $25^{\circ} \mathrm{C}$. Each measurement was performed in triplicate.

The powder morphologies were observed under a scanning electron microscope (VEGA TS 5163MM; TESCAN, Brno, Czech Republic) at an accelerating voltage of $20 \mathrm{kV}$. The matrix structures of the solutions of powder carriers and the model gel $(0.5 \% \mathrm{HEC})$ before and after the addition of powders (containing no nanoparticles) or solutions of powder carriers were observed at the same accelerating voltage, after lyophilization.

To measure the release of siRNA from dry powders, $25 \mu \mathrm{L}$ of nanoparticle suspension (loaded with $100 \mathrm{nM}$ Cy5siRNA before spray-drying or reconstitution) was added to $175 \mu \mathrm{L}$ of citrate buffer solution ( $5 \mathrm{mM}, \mathrm{pH} 4.5)$. The samples were incubated with $200 \mathrm{rpm}$ rotation at $37^{\circ} \mathrm{C}$ and centrifuged at $16,000 \times g$ for 20 minutes at the scheduled time points.

Table I Composition of powder formulations

\begin{tabular}{|c|c|c|c|c|}
\hline \multirow{2}{*}{$\begin{array}{l}\text { Formulation } \\
\text { code }\end{array}$} & \multirow{2}{*}{$\begin{array}{l}\text { E80/CS } \\
(\%, w / w)\end{array}$} & \multicolumn{3}{|c|}{ Powder carrier } \\
\hline & & $\begin{array}{l}\text { FI } 27 \\
(\%, w / w)\end{array}$ & $\begin{array}{l}\text { HPMC } \\
(\%, w / w)\end{array}$ & $\begin{array}{l}\text { Mannitol } \\
(\%, w / w) \\
\end{array}$ \\
\hline $\mathrm{FI}$ & 0.55 & 1 & 0 & 10 \\
\hline F2 & 0.55 & 0.6 & 0.1 & 10 \\
\hline F3 & 0.55 & 0.2 & 0.2 & 10 \\
\hline F4 & 0.55 & 0 & 0.25 & 10 \\
\hline
\end{tabular}

Abbreviations: CS, chitosan; E80, Lipoid E80; F, formulation; FI27, Pluronic FI27; HPMC, hydroxypropyl methyl cellulose.
The resulting supernatants were collected and fluorescence intensity was determined in a microplate reader (SynergyH1; BioTek Instruments Inc, Winooski, VT, USA).

\section{siRNA encapsulation and integrity assay}

The loading capability of each formulation, as well as the integrity of the encapsulated siRNA in the absence/presence of RNase A, was assessed by agarose gel electrophoresis. After suspending siRNA-containing powders in water, the samples for the integrity assay were treated with RNase A $(0.1 \mathrm{mg} / \mathrm{mL})$ for 1 hour at $37^{\circ} \mathrm{C}$ and then kept in water bath at $80^{\circ} \mathrm{C}$ for 10 minutes to inactivate the enzyme. Sodium dodecyl sulfate $(2 \%, w / v)$ was added to dissociate siRNA from the complexes. Subsequently, $10 \mu \mathrm{L}$ of each sample (containing $0.2 \mu \mathrm{g}$ of siRNA) was added to the wells of a $2 \%$ $(\mathrm{w} / \mathrm{v})$ agarose gel. Naked siRNA samples treated with and without RNase A were used as controls. After a 30-minute run at $80 \mathrm{~V}$, bands were imaged under ultraviolet (UV) light.

\section{Capillary penetration experiments}

The mucus penetration of E80/CS-NPs in different powder formulations was examined using the method described by Kuhn et al. ${ }^{23}$ In order to visualize the nanoparticles, rhodamine B isothiocyanate (RITC)-labeled chitosan (RITC-CS) was prepared and separated as follows: approximately $30 \mathrm{mg}$ RITC was dissolved in $1.5 \mathrm{~mL}$ methanol and added dropwise into $60 \mathrm{~mL}$ of $1 \%$ acetic acid solution of chitosan $(0.2 \% \mathrm{w} / \mathrm{v})$ and the reaction mixture was incubated overnight in the dark with stirring. To separate RITC-CS from free RITC, the mixture was dialyzed overnight with a cutoff of 8-14 kDa. E80/RITC-CS-loaded powder was prepared using the methods described earlier in the "Preparation of nanoparticle-loaded spray-dried powders" section.

Here, we filled capillaries with $0.5 \%$ HEC as a model gel; this was selected because of its chemical and microrheological similarities to mucins. ${ }^{24}$ Powders, or their solutions (before spray-drying), with an equivalent amount of E80/RITC-CS were pipetted onto one end of the gel column and the other end was sealed with vacuum grease. Capillaries loaded with E80/RITC-CS nanoparticles or different formulations were prepared and placed vertically at the same time. After 1 hour, their positions in the gel were recorded. This experiment was operated in dark.

\section{Rheological analysis}

The rheological analysis was carried out using a HAAKE MARS III rheometer (Thermofisher Scientific, Waltham, MA, USA) fitted with a $60 \mathrm{~mm}$ stainless steel parallel 
plate. Two milliliters of the test samples were loaded onto the platform and equilibrated at $37.2^{\circ} \mathrm{C}$ for 5 minutes. The oscillatory measurements were performed in the linear viscoelastic range over a frequency range of $10-0.1 \mathrm{~Hz}$, with a constant stress of $1 \mathrm{~Pa}$.

\section{In vitro mucoadhesion assay}

Female New Zealand albino rabbits $(3-4 \mathrm{~kg})$ were provided by the Animal Experimental Center of the Shanghai Institute of Materia Medica. All the animal experiments were carried out according to the Institutional Animal Care and Use Committee (IACUC) guidelines, and were approved by the ethics committee of the Shanghai Institute of Materia Medica.

The bioadhesive test system was established according to the method described by Rango Rao and Buri. ${ }^{25}$ Female New Zealand albino rabbits were killed by injecting an overdose of sodium pentobarbital. The vaginal tissue of the rabbit was immediately removed and cut into $3 \mathrm{~cm}$ pieces longitudinally; these tissue preparations were placed on a stainless steel support. Thirty milligrams of Cy5-siRNAloaded powders were weighed accurately and spread on the mucosal surface through a 40-mesh sieve. The tissue support was kept at $92.5 \%$ relative humidity at room temperature for 20 minutes. Then, $5 \mathrm{mM}$ citrate buffer solution ( $\mathrm{pH} 4.5$ ) was pushed out from a syringe by an automatic pusher at a constant rate of $0.2 \mathrm{~mL} / \mathrm{min}$, to wash the tissue surface thoroughly for 30 minutes. The effluent was collected into a beaker and dissolved sufficiently. The fluorescence intensity of the solution was measured in a microplate reader and the mucoadhesive fraction was calculated using the fluorescence intensity of $5 \mathrm{mg} / \mathrm{mL}$ powder in citrate buffer solution as a control.

\section{In vivo delivery of siRNA in the rat vaginal tract}

Lewis (6-8-week-old) female rats (weighing around $200 \times g$ ) were provided by the Animal Experimental Center of the Shanghai Institute of Materia Medica. To investigate the efficacy of vaginal siRNA delivery, estrous phase rates were anesthetized with an intraperitoneal injection of sodium pentobarbital. Formulations containing $33 \mu \mathrm{g}$ of Cy5-siRNA (both in powder and in solution forms) were administered to the vaginal tract. E80/CS-NPs loaded with an equal amount of Cy5-siRNA were administered as a control. One hour after administration, the rats were killed and the vaginas were excised and immersed in Tissue-Tek OCT compound. Sections were cut at a thickness of $10 \mu \mathrm{m}$ using a Leica CM-1950 (Leica Microsystems, Wetzlar, Germany), fixed in 4\% paraformaldehyde, and stained with 4, 6-diamidino2 -phenylindole to visualize the cell nuclei. Fluorescence photomicroscopes of the sections were obtained using an OLYMPUS IX-70 microscope (Olympus Corporation, Tokyo, Japan). The relative fluorescence intensity was calculated using ImageJ software.

\section{Statistical analysis}

All data are expressed as mean \pm standard deviation (SD). Statistical analysis was carried out via two-way analysis of variance (ANOVA) tests using the SPSS software (SPSS Inc, Chicago, IL, USA). A value of $P<0.05$ was considered as statistically significant; $P<0.01$ and $P<0.01$ was considered as very significant.

\section{Results and discussion Characterization of powders}

The formulations were designed based on the viscosities of the solutions prior to spray-drying. Viscosity measurement revealed that in the low concentration range, the viscosity of F127 was equal to that of HPMC at a F127:HPMC ratio of $4: 1$, w/w (data not shown). Thus, the compositions of the formulations were designed as shown in Table 1. As expected, these four formulations showed close viscosity values (Figure 1).

Analysis of powder morphology (Figure 2) showed relatively separate, spherical, particles with no aggregation in each of the spray-dried formulations. The diameters of the

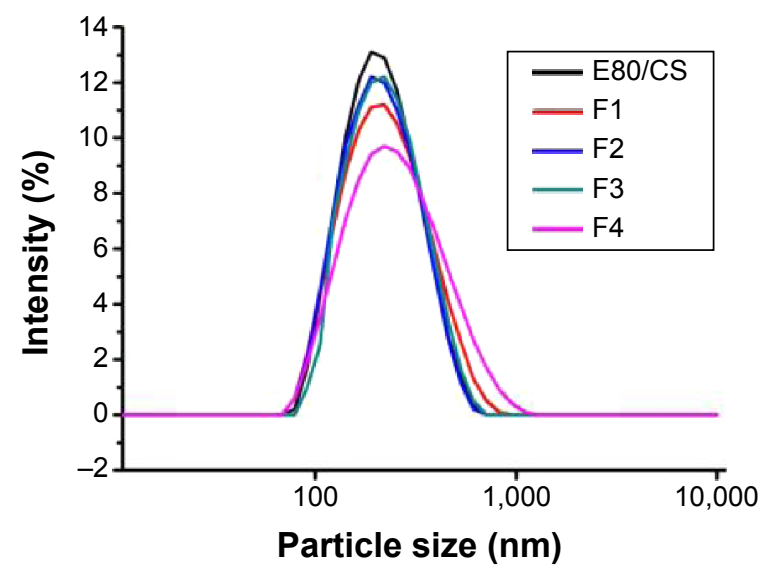

\begin{tabular}{|llll|}
$\begin{array}{l}\text { Formulation } \\
\text { code }\end{array}$ & $\begin{array}{l}\text { Viscosity } \\
(\mathrm{mPa} \cdot \mathrm{s})\end{array}$ & $\begin{array}{l}\text { Powder size } \\
(\mu \mathrm{m})\end{array}$ & $\begin{array}{l}\text { Particle size } \\
(\mathrm{nm})\end{array}$ \\
\hline E80/CS & NA & NA & $182.3 \pm 9.1$ \\
\hline F1 & $2.79 \pm 0.03$ & $9.75 \pm 5.4$ & $191.0 \pm 13.5$ \\
\hline F2 & $2.73 \pm 0.03$ & $6.21 \pm 3.9$ & $189.2 \pm 8.0$ \\
\hline F3 & $2.70 \pm 0.03$ & $7.83 \pm 2.6$ & $187.4 \pm 10.2$ \\
\hline F4 & $2.82 \pm 0.03$ & $7.56 \pm 2.4$ & $195.8 \pm 5.1$ \\
\hline
\end{tabular}

Figure I The viscosity of the solution formulations (before spray-drying), the sizes of the powders, and the particle size distribution of the reconstituted nanoparticles from the dry powders.

Notes: Mean \pm SD; $n=3$.

Abbreviations: CS, chitosan; E80, Lipoid E80; F, formulation; NA, not applicable. 

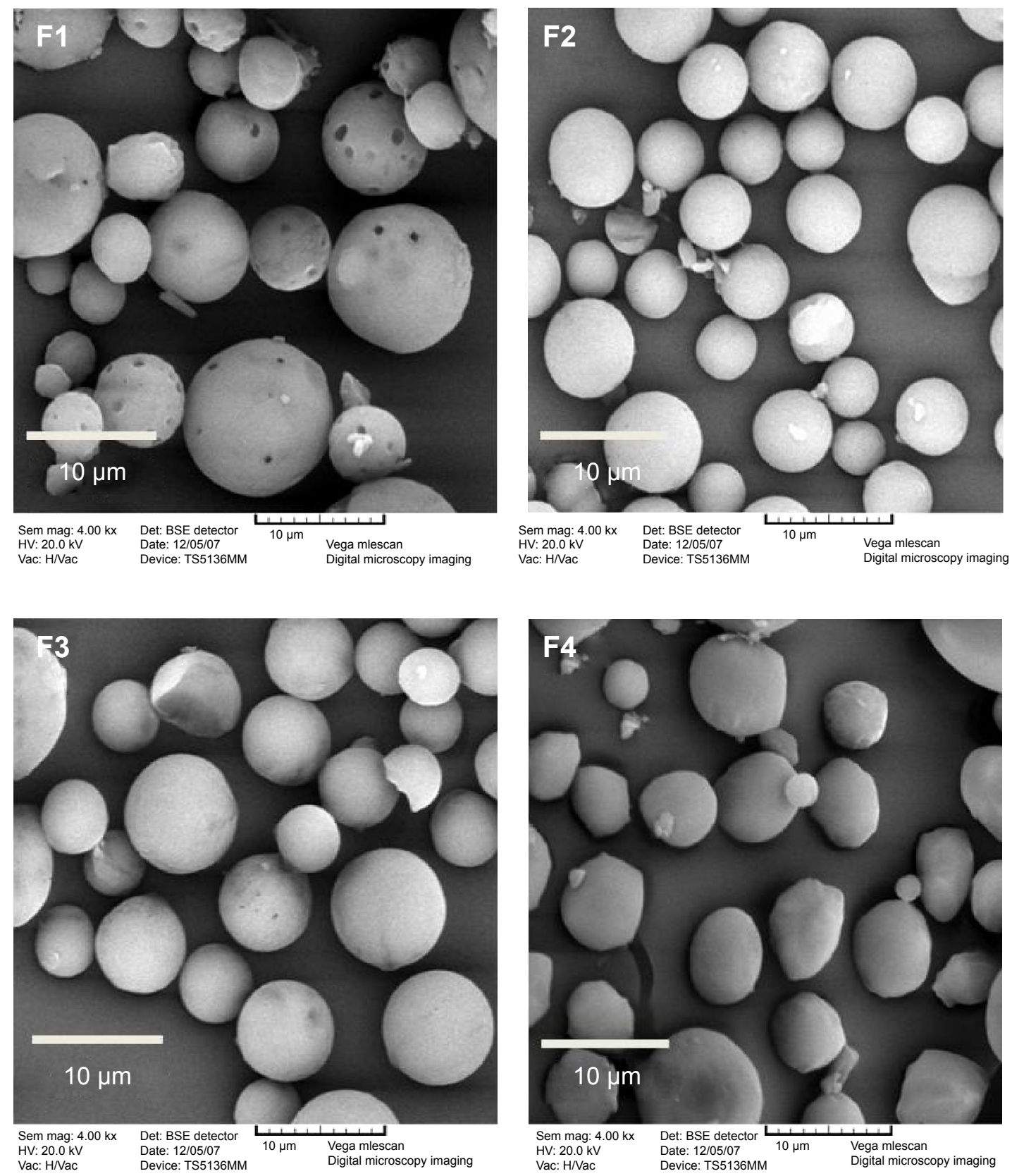

Figure 2 Scanning electron microphotographs of spray-dried powders.

Note: Scale bar: $10 \mu \mathrm{m}$.

Abbreviations: F, formulation; HV, high voltage; Sem mag: scanning electron microscopy magnification; Vac: vacuum.

powders ranged from 5 to $15 \mu \mathrm{m}$ and there were no significant differences between these formulations in this respect. These results were consistent with the values determined by a laser particle sizer (Figure 1); this similarity in size might relate to their similar viscosity. In contrast to the other three formulations, randomly distributed pores were observed on the surfaces of F1, and F4 formed irregular particles with decreased roundness. These subtle differences between the particles related to the properties of the materials used in the formulations. The high dispersion and small sizes of the powders would contribute to effective spreading of the powders onto the surface of vaginal tract and the subsequent wetting by vaginal liquid.

The particle sizes of the reconstituted nanoparticles were also measured after spray-drying. The loaded E80/CS-NPs were $182.3 \pm 9.1 \mathrm{~nm}$ with core-shell structures (Figures 1 and S2). Reconstituted nanoparticles of the four formulations showed similar sizes of around $190 \mathrm{~nm}$; this size similarity to E80/CS-NPs suggested that the nanoparticles remained structurally intact after spray-drying.

Since the pore sizes of human cervicovaginal mucus range from approximately 50 to $1,800 \mathrm{~nm},{ }^{11}$ particles with 
sizes larger than the pores of the mucus network will fail to pass through the barrier layer. The particle sizes control the ability of the particles to fit within the mucus mesh pores and play a crucial role in mucus penetration. Strategy that focused on delivering particles with a fit particle size to prevent mucus entrapment has been developed. However, this strategy would limit the use of some particles with unfit sizes, thus alternative strategies are required.

\section{Effective siRNA entrapment and protection in powders}

Agarose gel electrophoresis was used to evaluate the encapsulation ability of the formulations, as well as their protection of siRNA. The migration of siRNA was prevented by powders F1-F4 (Figure 3, lanes 2-5), indicating that all of the powders encapsulated siRNA effectively. The siRNA integrity was investigated after treating the formulations with RNase A. Although naked siRNA was degraded completely after 1 hour (Figure 3, lane 6), siRNA within all the formulations remained intact (Figure 3, lanes 7-10), suggesting that these carrier systems offered effective protection of siRNA against physical degradation and also enzymatic digestion.

The protective properties of the powders may operate via two mechanisms. Firstly, the powder excipients constituted the main fraction of the formulations and were present at a significantly higher level than the loaded nanoparticles; this might contribute to a high dispersion of E80/CS-siRNA within the powders. As water evaporated during the spraydrying process, the excipients tended to surround the nanoparticles quickly and preserve them from the high temperatures $\left(\sim 120^{\circ} \mathrm{C}\right)$ and sustained shear forces involved in this process. Secondly, the core-shell structure of the E80/CS-NPs could

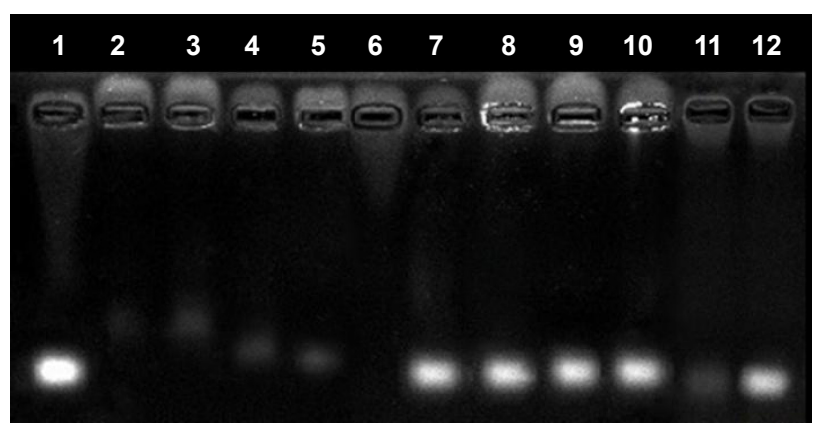

Figure 3 Agarose gel electrophoresis for the analysis of siRNA loading efficiency and integrity.

Notes: Lanes I-5 and II: naked siRNA, siRNA-loaded FI-F4, and E80/CS nanoparticles; lanes 6-10 and I2: naked siRNA, siRNA-loaded FI-F4, and E80/CS nanoparticles treated with RNase $A$ and displaced by $2 \%$ SDS.

Abbreviations: CS, chitosan; E80, Lipoid E80; F, formulation; SDS, sodium dodecylsulfate; siRNA, small interfering RNA. protect the siRNA from direct contact with RNase and thus prevent its enzymatic digestion (Figure 3, lane 12). These results were consistent with a previous report. ${ }^{26}$ The protection of the loaded siRNA provided by the liposomal shell, together with the powder carriers, was crucial for effective delivery.

\section{Sustained release of siRNA from the powders}

The in vitro release profiles of siRNA from the nanoparticles and powders (before and after spay-drying) were investigated in citrate buffer ( $5 \mathrm{mM}, \mathrm{pH} 4.5)$ and determined by fluorescence analysis. In Figure 4, the cumulative release of siRNA from formulations containing F127 (F1-F3) reached over $30 \%$ after 4 hours and was similar to that of the E80/CS-NPs, suggesting that the spray-drying process did not disrupt the liposome bilayer structure. This result was consistent with that obtained in the electrophoresis experiment. Nevertheless, less than $20 \%$ of loaded siRNA was released from F4 during the test period. These distinct release rates from the formulations may reflect their network structures, which are formed by polymer cross-linking. All of the formulations showed sustained release characteristics.

The sustained release of siRNA from powder dosage forms might attribute to the core-shell structure of the E80/ CS-NPs; this structure might reduce the premature release of encapsulated siRNA before reaching the target cells. The sustained release behavior would enhance patient compliance with topical treatment of vaginal diseases and ensure continued therapeutic efficacy, with reduced side effects.

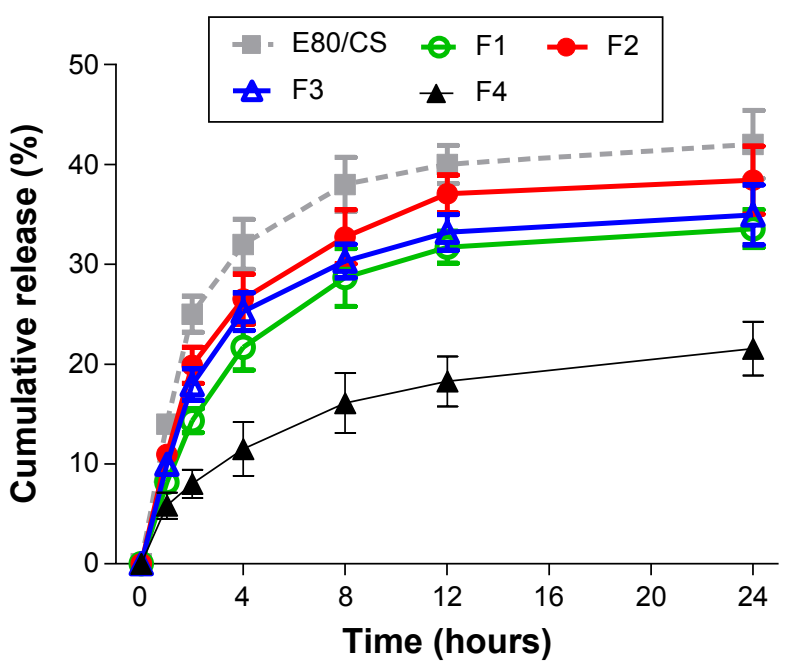

Figure 4 Release profiles of Cy5-siRNA from E80/CS nanoparticle and FI-F4 powders in citrate buffer solution (5 mM, pH 4.5).

Abbreviations: CS, chitosan; E80, Lipoid E80; F, formulation; siRNA, small interfering RNA. 
The frequency of the repeated administration would reduce, which contributed to a less effect on the barrier properties of mucus to pathogens.

\section{Different penetrating properties of powders and solutions}

To determine the penetration properties of the formulations, we applied a modified capillary method. E80/CS-NPs were visualized using RITC-labeled chitosan. The powders showed notable differences in their penetration velocity within 1 hour (Figure 5). The nanoparticles loaded in F2 almost reached the bottom end of the capillary within 1 hour, followed by the F1 nanoparticles. F4 showed the shortest distance of nanoparticles translocation through the gel. In contrast, the solution formulations (before spray-drying) showed no differences in this respect and all behaved similarly to the E80/CS-NPs.

Investigation of penetration behavior using this capillary model may predict the potential of the nanoparticles to pass

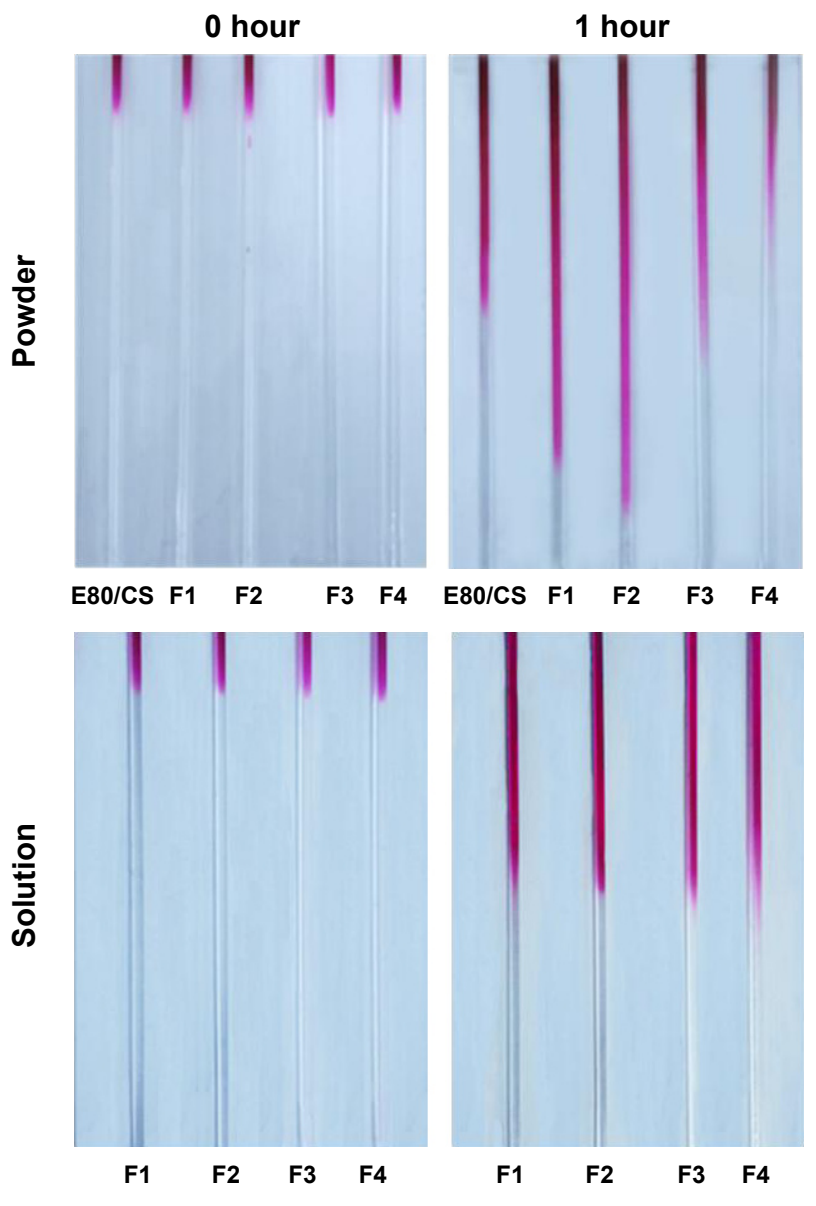

Figure 5 Penetration of RITC-CS-loaded E80/CS nanoparticles, FI-F4 powders, and solutions through $0.5 \% \mathrm{HEC}$ gel within I hour.

Abbreviations: CS, chitosan; E80, Lipoid E80; F, formulation; HEC, hydroxyethyl cellulose; RITC-CS, rhodamine B isothiocyanate-labeled chitosan. through physiological mucus barriers. Differences in penetration might relate to the molecular sieve effect and/or interactions between the nanoparticles and the gel matrix. Since the nanoparticles loaded in different formulations were the same and the nanoparticles reconstituted from different powder formulations had similar sizes (Figure 1), it is assumed that the differences in penetration performance may be related to some changes in the model gel.

\section{The effects of powder formulations on model gel structure}

In order to examine the changes in model gels exposed to these formulations intuitively, we observed the morphologies and structures of the freeze-dried samples. As shown in Figure 6, all of the samples exhibited cross-linked structures with randomly arranged fiber networks and different pore sizes. The observed structures of the powder carrier solutions provided possible explanations for the differences in the release of siRNA. F4 showed a network with a higher degree of cross-linking, resulting in more difficult release of the nanoparticles from the F4 network and thus a lower siRNA release rate. In contrast, the potential formation of an inter-polymer complex between F127 and HPMC contributed to a more regular honeycomb-like network with expanded pore sizes in F2 and F3, which might allow for easier release of nanoparticles.

As anticipated, when spray-dried powders were added to the model gel, the HEC fiber network was altered (Figure 6A, F-I). Typically, the mesh pore sizes of the gel expanded from approximately $100 \mu \mathrm{m}$, to over $200 \mu \mathrm{m}$, when mixed with F2. Unlike the powders, the solutions of all the formulations produced little change in the fiber structures and there were almost no differences between the groups (Figure 6J-M). These powder-induced changes in model gel structure were consistent with the results of the capillary penetration experiment (Figure 5). The significantly enlarged pore sizes of the gel matrix facilitated the transportation of F2 powder-loaded nanoparticles through the gel barrier; this contributed to more rapid penetration. These results suggested that the molecular sieve effect was a primary determinant of nanoparticle mucus penetration.

The distinct effects of the powder and solution formulations on mucus gel might result from their modification of water extracting capacity and the dilution effect. As reported previously, dry formulations containing materials with a high affinity for water adhere to the wet mucosal surface by extracting the water from mucus; subsequent inter-diffusing with the mucus layer ${ }^{27}$ may reconstitute the mucus matrix. 

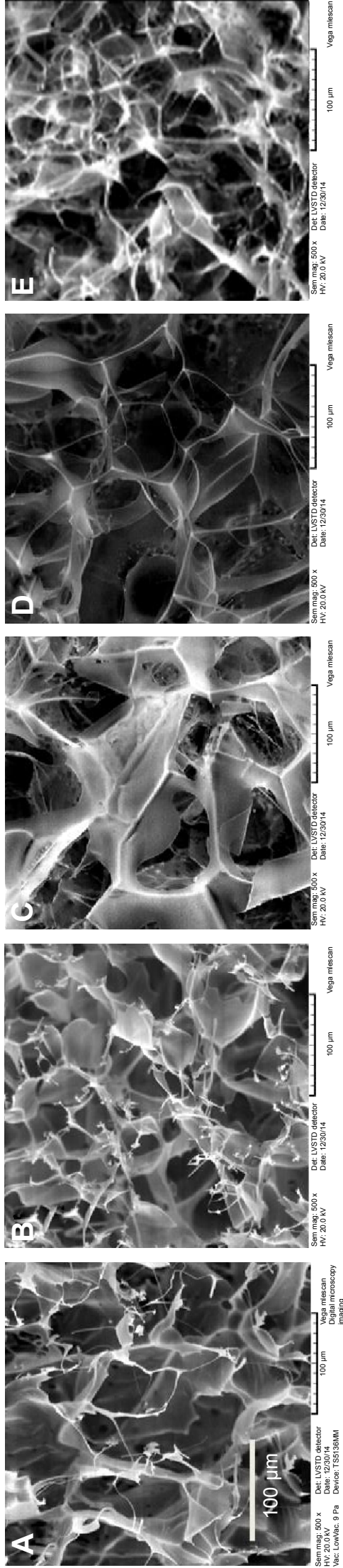
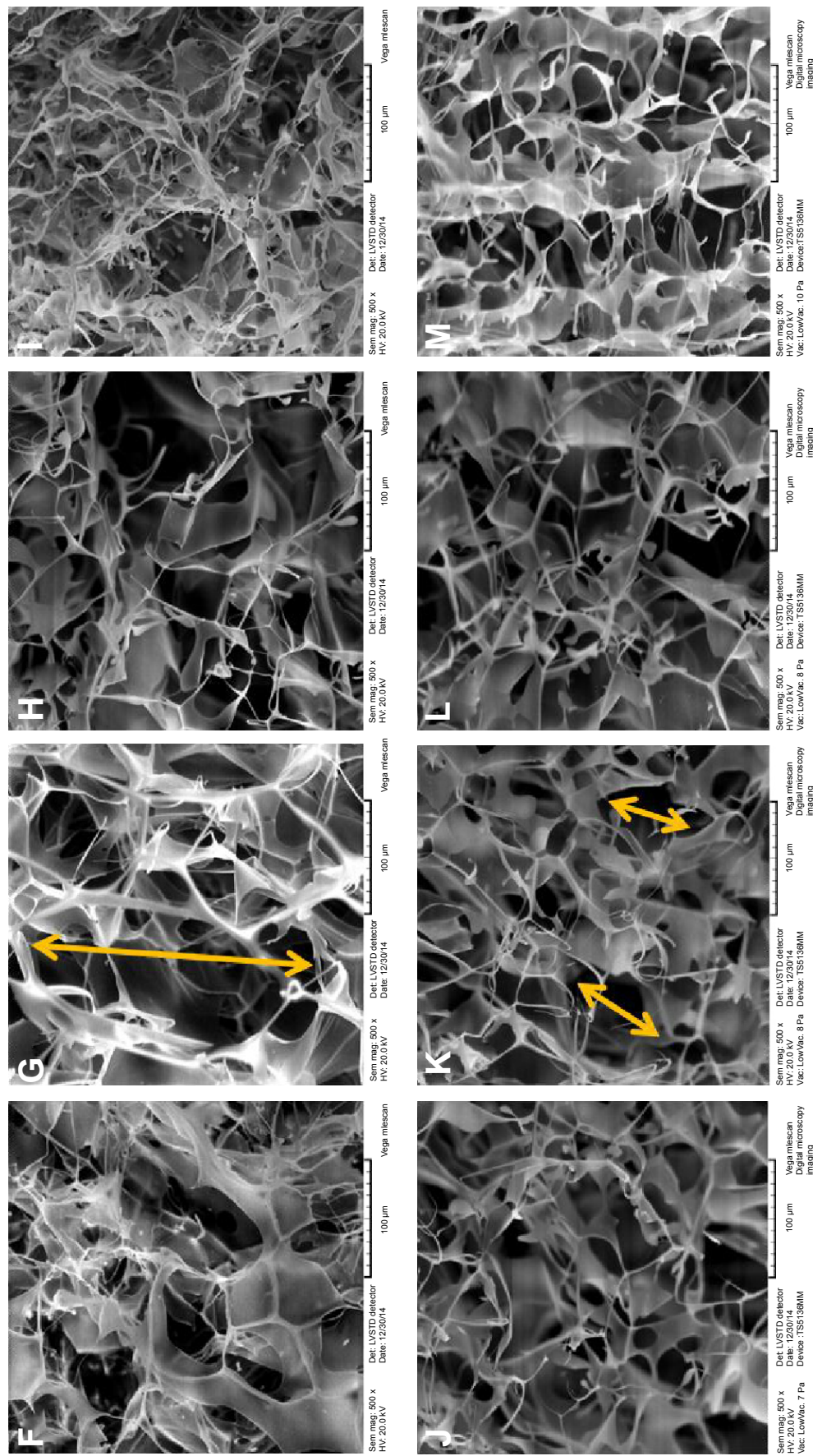

它 $\overline{\mathrm{c}}$

닐

응 ㅇํㅇ

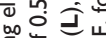

豆政

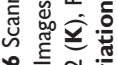

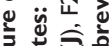

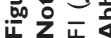


Powder formulations containing mannitol, a soluble carrier material that can absorb moisture and dissolve rapidly, facilitate swelling and subsequent spreading of powders on the mucosal surface. However, water uptake is lower for solutions and their dilution effects result in a lower concentration of the bonds that can interact with mucin, thus reducing mucus matrix modification.

Some previous studies have found that polymer molecules such as low-molecular-weight guluronic acid oligomers, ${ }^{28}$ poly vinyl pyridine, and polyethylene glycol ${ }^{10}$ could alter the rheological properties or the network structures of mucus. These mucus alterations through electrostatic competitive inhibition or hydrogen bonds led to the formation of novel coalesced fibers with mucus. Accordingly, some approaches to the improvement of nanoparticle mobility in mucus matrices, based on the molecular sieve mechanism, have been introduced. ${ }^{29}$ In the present study, we found that the powders, rather than the solutions, of formulations containing an appropriate ratio of F127 and HPMC had the potential to alter the vaginal mucus matrix and thus modify the molecular sieve effect, facilitating nanoparticle penetration. In addition to providing easier vaginal administration, this potential to alter the steric barrier posed by mucus offers some promise for the use of spray-dried powders in vaginal drug delivery.

\section{Alterations of model gel rheological properties}

To investigate the mechanisms involved in the formulationmediated effects on model gel structure, the rheological properties of the samples (containing no nanoparticles) were measured and characterized by the investigation of two dynamic moduli: the elasticity modulus, $\mathrm{G}^{\prime}$ (storage modulus), and the viscosity modulus, $G^{\prime \prime}$ (loss modulus). Dynamic analysis revealed the changes on viscoelastic properties of the model gel in the frequency dependence caused by the addition of formulations; this might reflect the changes on microstructure of the gel. ${ }^{28}$

In order to discriminate between the curves, we moved them to distinguishable areas and labeled the ordinates with arbitrary units. As shown in Figure 7, all the curves showed a crossover point, where $\mathrm{G}^{\prime}=\mathrm{G}^{\prime \prime}$, and $\mathrm{G}^{\prime \prime}$ increased at higher frequencies. The crossover point for the $0.5 \%$ HEC solution was at $2.045 \mathrm{~Hz}$. After being mixed with any formulations, the crossover points of the mixtures shifted to a lower frequency region, which meant that the elastic behavior was prevailing over the viscous behavior. When they were mixed with HEC, F2 and F4 caused a larger shift to $0.298 \mathrm{~Hz}$ and $0.332 \mathrm{~Hz}$, respectively, while F3 showed the smallest shift to $0.692 \mathrm{~Hz}$. The shifts caused by the same solution formulations were relatively smaller and there was little difference between the formulations. The degree of shift of the crossover points coincided with the alterations in gel structures. Comparison of the corresponding scanning electron micrographs (Figure 6) showed that formulations producing the larger/smaller rheological shift produced greater/lesser (respectively) changes in the gel structure. These results validated that the addition of the formulation caused alterations of model gel rheological properties, which might partly explain the alterations of the structures.

Rheological behavior is influenced by various properties of the samples and has thus been widely analyzed and shown to provide a powerful tool for the assessment and prediction of the behavior of vaginally administered preparations. The interactions between polymeric materials and mucus include physical entanglement, hydrogen bonding, electrostatic, and hydrophobic interactions. ${ }^{30}$ The rheological behavior of the test samples reflects these physical or/and chemical interactions. Dilution also significantly influences the rheological properties. ${ }^{31}$ When the formulation solutions were added to the model gel solution, the gel was diluted, reducing the strain responding to the oscillatory stress. However, the dry powders circumvented the dilution effect, resulting in higher dynamic moduli.

\section{Mucoadhesive properties of powders}

The mucoadhesive properties of powders was investigated in an ex vivo experiment and operated on the rabbit vaginal explants. In order to simulate the biological flow through mucous membranes, citrate buffer solution (5 mM, pH 4.5) was used as a simulated fluid. Despite their equal viscosities, F1-F4 powders showed different mucoadhesive properties. The adherent fractions of these formulations ranged from approximately $56 \%$ for $\mathrm{F} 1$ to $85 \%$ for $\mathrm{F} 4$, which contained $0.25 \%$ HPMC (Figure 8). This stronger adhesion of $\mathrm{F} 4$ may reflect interactions between the carrier materials and mucus.

HPMC is a semi-synthetic derivative of polysaccharide cellulose and commonly used for topical and mucosal drug delivery because it is nontoxic and nonirritating. Furthermore, HPMC was reported to possess good mucoadhesive properties in the solid state ${ }^{32}$ and this mucoadhesive behavior is likely to be associated with physical chain entanglement with mucus. ${ }^{33}$ In the present study, we found that the powder containing $0.25 \%$ HPMC (F4) change the model gel markedly (Figure 6I). The rheology results confirmed that F4 interacted strongly with the gel, which might result in lower particle diffusion rates. 

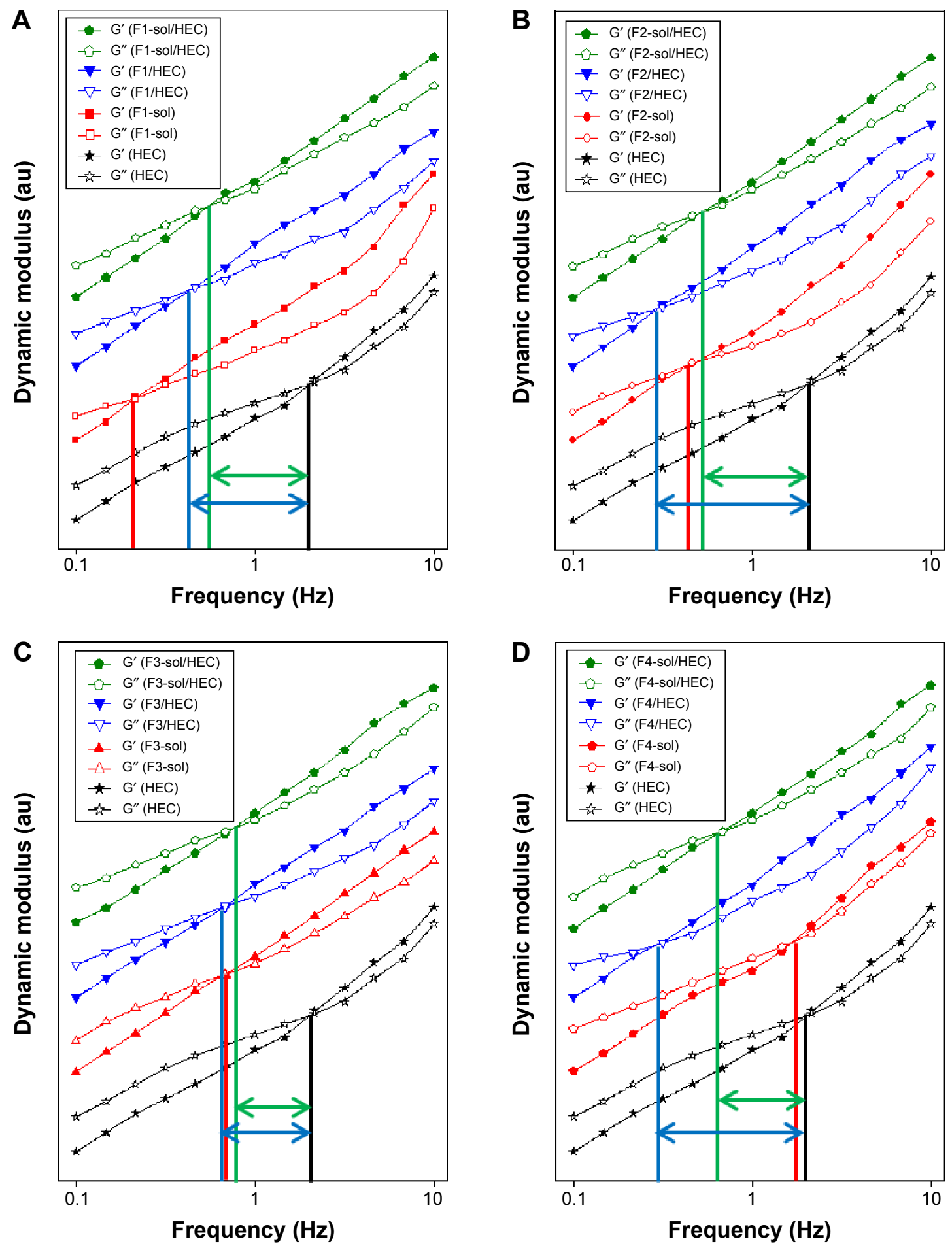

Figure 7 Frequency dependence of the viscoelastic moduli.

Notes: Viscoelastic moduli of $0.5 \%$ HEC, solutions of FI (A), F2 (B), F3 (C), and F4 (D) powder carriers (eg, FI-sol), $0.5 \%$ HEC after the addition of FI-F4 powders (containing no nanoparticles) (eg, $\mathrm{FI} / \mathrm{HEC}$ ), and $0.5 \% \mathrm{HEC}$ after the addition of $\mathrm{FI}-\mathrm{F} 4$ powder carrier solutions at $37.2^{\circ} \mathrm{C}$. The arrows indicate the degree of shift of the crossover points for the $0.5 \%$ HEC solution, after being mixed with powder formulations (the blue arrows), or the same solution formulations (the green arrows).

Abbreviations: F, formulation; HEC, hydroxyethyl cellulose; sol, solution.

\section{Enhanced powder-mediated vaginal siRNA delivery}

To evaluate the in vivo performance of these formulations, vaginal sections from treated estrous phase rats were frozen and observed under confocal microscopy. As shown in Figure 9, there were noticeable differences in siRNA delivery in rats treated with different formulations of spray-dried powders. Compared to other groups, $\mathrm{F} 2$ produced a significantly higher intensity of red fluorescence, which was almost 17.8 times higher than the levels produced in animals treated with E80/ 


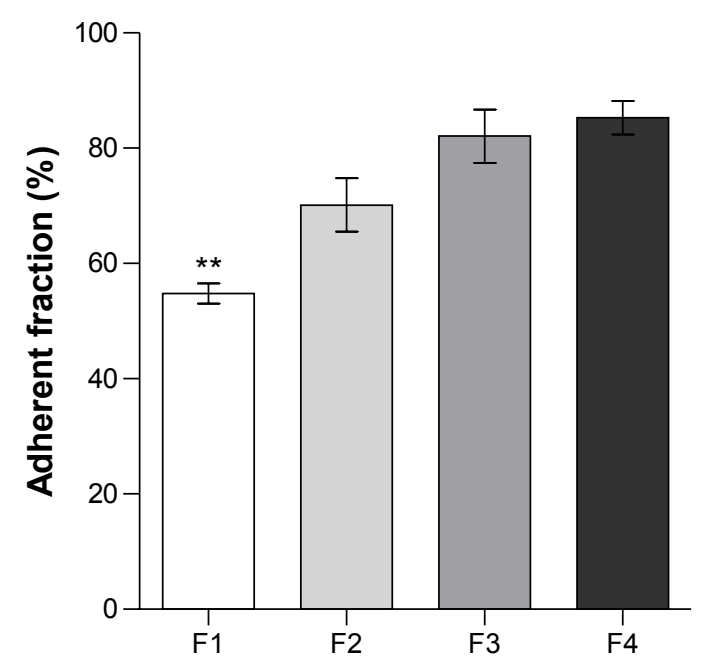

Figure 8 Mucoadhesive properties of cy5-siRNA-loaded dry powders. Note: $* * P<0.0$ l compared with F2-F4.

Abbreviations: F, formulation; siRNA, small interfering RNA.
CS-siRNAs (Figure 9B). Moreover, the red fluorescence was distributed at the surface of the vaginal epithelium and also penetrated into the tissue (Figure 9A). These excellent results offer some promise for significant siRNA response over the vaginal epithelium. However, the other formulations produced less siRNA delivery in vaginal tissue. The E80/ CS-NPs were trapped by the mucus and aggregated in the vaginal lumen. This result was consistent with those of some previous studies, ${ }^{3,34}$ confirming that liposomes have difficulty penetrating through the mucus barrier. Although the F1 nanoparticles penetrated across the epithelial cells, their delivery was limited by low mucoadhesion. These results suggested that both the mucoadhesive and mucus-penetrating properties of carrier systems play a role in vaginal administration. In contrast, there were almost no differences between groups of rats administered the solution formulations. Even for F2,
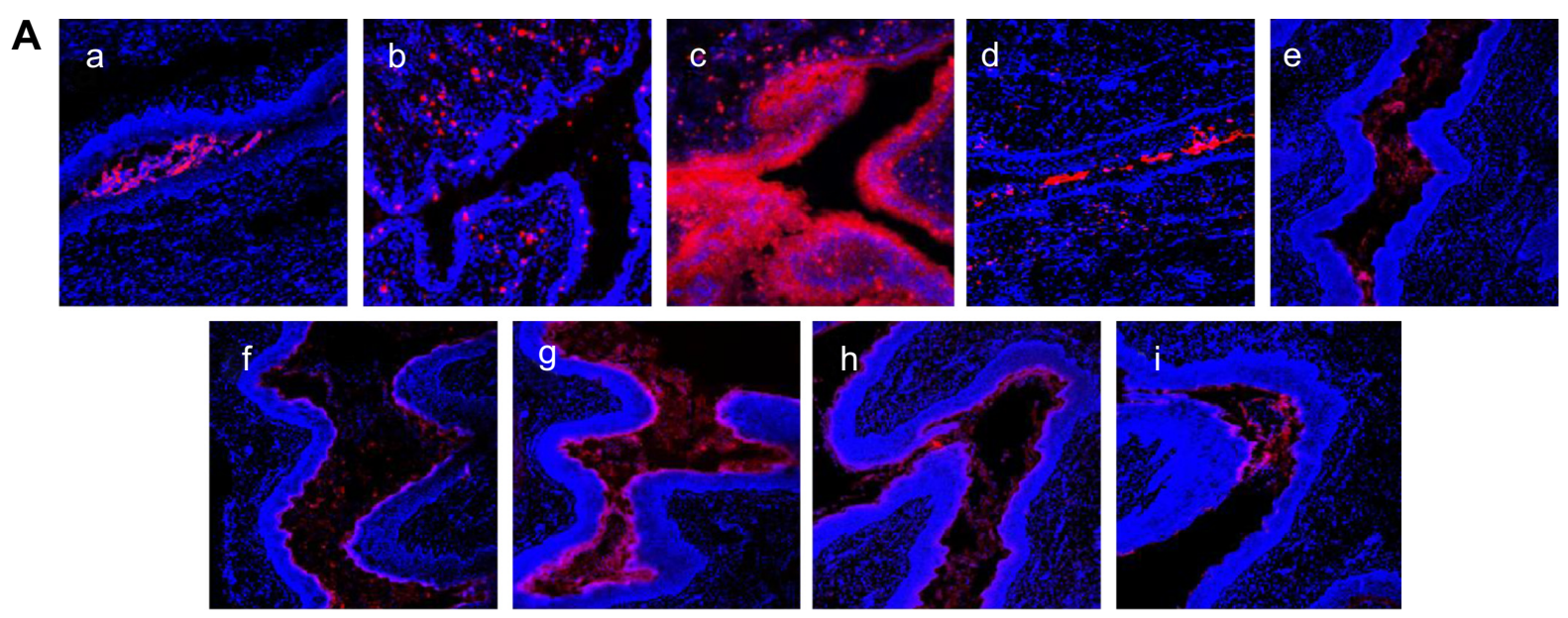

B a

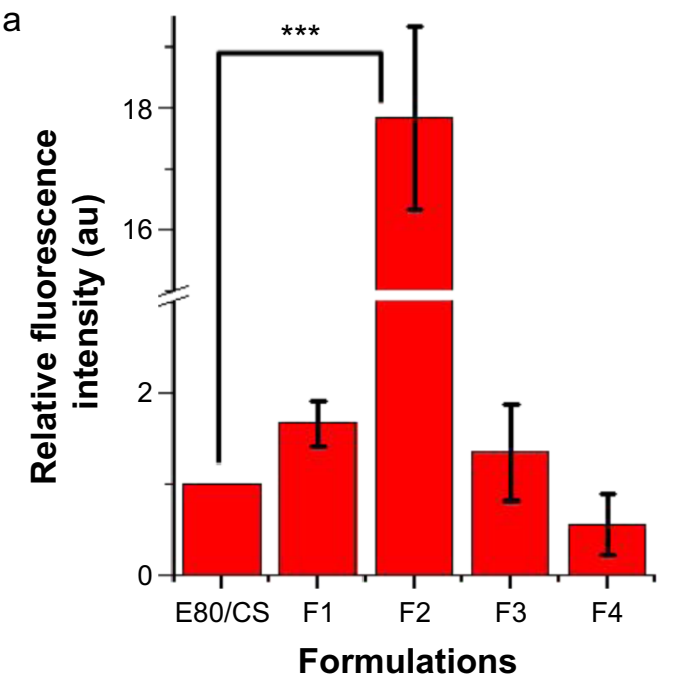

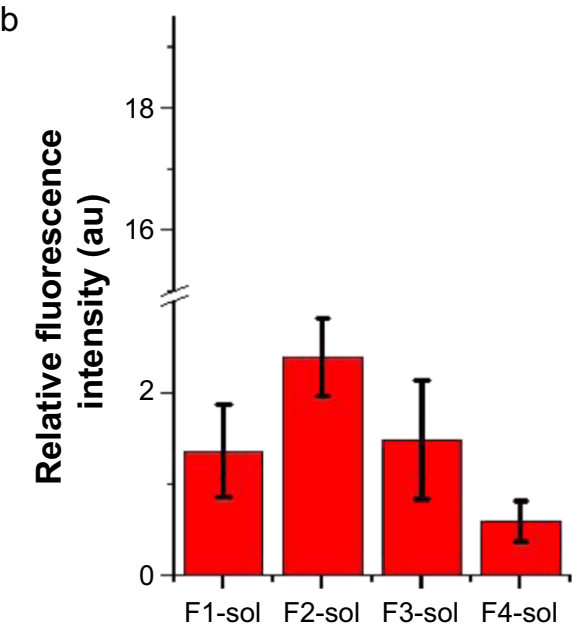

Formulations

Figure 9 Vaginal siRNA delivery of different formulations.

Notes: (A) Distribution of cy5-siRNA in vaginal tissue of estrus phase rats after I hour administration of E80/CS nanoparticles (a), spray-drying powders of FI (b), F2 (c), F3 (d), and F4 (e), and the solutions of FI (f), F2 (g), F3 (h), and F4 (i). (B) Relative fluorescence intensity of FI-F4 powders (a) and their solutions (b) compared to the E80/ CS nanoparticles in vagina $(* * * P<0.001)$.

Abbreviations: CS, chitosan; E80, Lipoid E80; F, formulation; siRNA, small interfering RNA; sol, solution. 


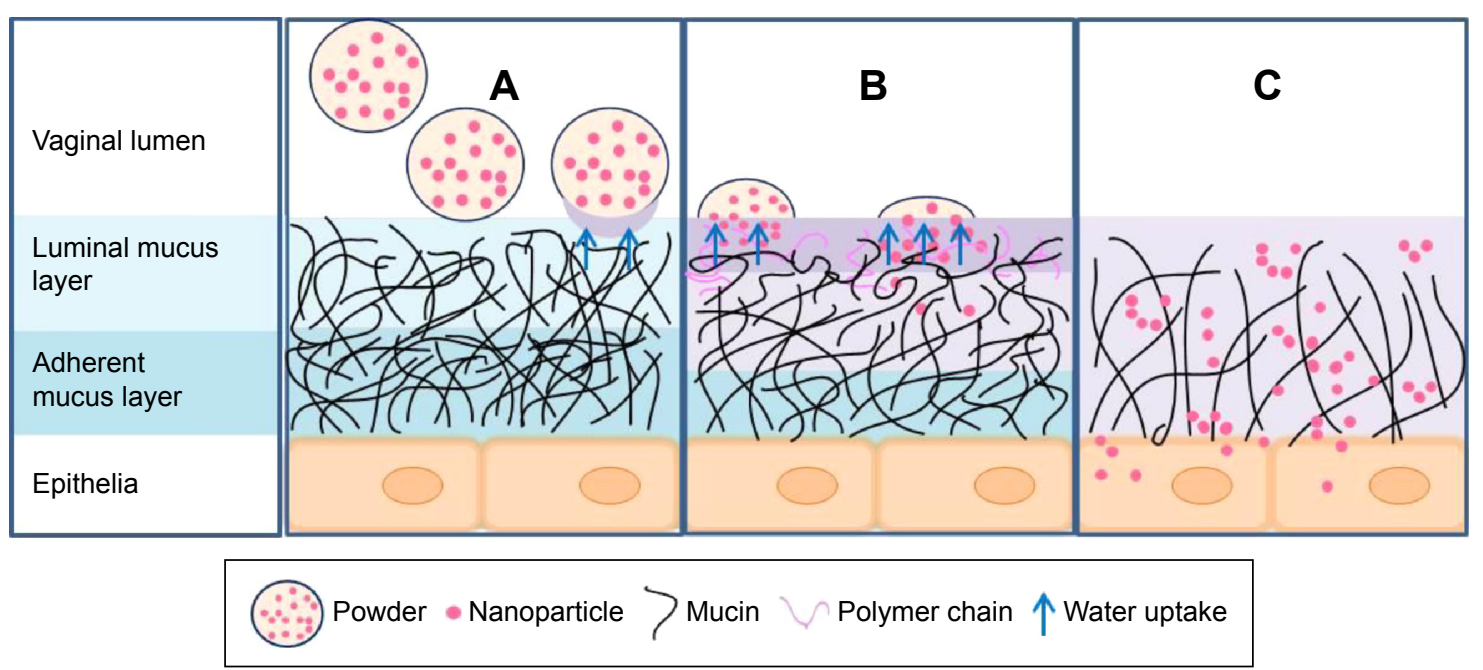

Figure 10 Schematic diagram of the powders administration in vaginal tract.

Notes: The powders spread out on the mucus layer and take up water from the mucus (A). Then the powders dissolve the lipid nanoparticles released from the powders and the polymer chains inter-diffuse with the mucin (B). The mucus matrix is altered by the powder carriers. The enlargement of the pore sizes of the network facilitates the nanoparticles penetrating through the mucus barrier, and distributing deeply into the epithelial cells (C).

poor vaginal siRNA delivery and severe entrapment in the vaginal lumen was observed (Figure 9A).

These results were consistent with the alterations of gel structure caused by these formulations (Figure 6). As illustrated in Figure 10, when spray-dried powders are administrated to the vaginal tract, the water-soluble mannitol absorbs water from the mucus, accelerating swelling and spreading of the powder on the vaginal mucus layer. The powder carriers dissolved and formed fluid gels with network structure (Figure 6). Water uptake from the mucus, coupled with polymer interactions with the vaginal mucus, alters the mucus matrix. Thus, the nanoparticles passed through the mucus layer because of powder-induced changes to the molecular sieve effect. The core-shell structure of the nanoparticles could protect siRNA from RNase digestion and reduce the premature release of encapsulated siRNA before reaching the target cells. When the siRNA-loaded nanoparticles reached the epithelial cells, the nanoparticle-borne siRNA was then released and specific gene silencing initiated along with the uptake of nanoparticles by the cells. However, the higher water content in the solution formulations impaired their ability to absorb water and diluted the systems to some extent, resulting in a reduction in their ability to alter mucus structure. Formulations lacking this capability to alter the mucosal matrix showed little mucus penetration and were subjected to elimination by vaginal clearance mechanisms, resulting in inefficient siRNA delivery.

\section{Conclusion}

In this study, we designed four formulations of spray-dried powders using different composition of F127 and HPMC and tested their siRNA delivery to the vagina. The dry powders showed potential capacities to alter the network structures of vaginal mucus. Enlargement of the mesh pore sizes of the mucosal matrix might contribute to the significantly improved nanoparticle-mediated epithelial siRNA delivery, because this altered the molecular sieve effect. However, these effects were not produced by solution formulations, which did not absorb water from the mucus. These results provide a new insight into the design of formulations for vaginal administration and indicate that spray-dried powders capable of altering the mucus network architecture have the potential to improve mucus penetration and epithelial delivery.

\section{Acknowledgments}

We are grateful for the financial support of CAS equipment development project (grant YZ201244), Natural Science Foundation of China (grant 81373356), and Youth Innovation Promotion Association, CAS.

\section{Disclosure}

The authors report no conflicts of interest in this work.

\section{References}

1. Palliser D, Chowdhury D, Wang QY, et al. An siRNA-based microbicide protects mice from lethal herpes simplex virus 2 infection. Nature. 2006; 439(7072):89-94.

2. Wu Y, Navarro F, Lal A, et al. Durable protection from herpes simplex virus-2 transmission following intravaginal application of siRNAs targeting both a viral and host gene. Cell Host Microbe. 2009;5(1): 84-94.

3. Wu SY, Chang HI, Burgess M, McMillan NAJ. Vaginal delivery of siRNA using a novel PEGylated lipoplex-entrapped alginate scaffold system. J Control Release. 2011;155(3):418-426. 
4. Wu SY, McMillan NAJ. Lipidic systems for in vivo siRNA delivery. AAPS J. 2009;11(4):639-652.

5. Sun S, Wang M, Knupp SA, et al. Combinatorial library of lipidoids for in vitro DNA delivery. Bioconjugate Chem. 2012;23(1):135-140.

6. Sun S, Wang M, Alberti KA, Choy A, Xu QB. DOPE facilitates quaternized lipidoids (QLDs) for in vitro DNA delivery. Nanomedicine. 2013; 9(7):849-854.

7. Woodrow KA, $\mathrm{Cu}$ Y, Booth CJ, Saucier-Sawyer JK, Wood MJ, Saltzman WM. Intravaginal gene silencing using biodegradable polymer nanoparticles densely loaded with small-interfering RNA. Nat Mater. 2009;8(6):526-533.

8. Steinbach JM, Weller CE, Booth CJ, Saltzman WM. Polymer nanoparticles encapsulating siRNA for treatment of HSV-2 genital infection. J Control Release. 2012;162(1):102-110.

9. Yang S, Chen Y, Ahmadie R, Ho EA. Advancements in the field of intravaginal siRNA delivery. J Control Release. 2013;167(1):29-39.

10. Willits RK, Saltzman WM. Synthetic polymers alter the structure of cervical mucus. Biomaterials. 2001;22(5):445-452.

11. Lai SK, O'Hanlon DE, Harrold S, et al. Rapid transport of large polymeric nanoparticles in fresh undiluted human mucus. Proc Natl Acad Sci U S A. 2007;104(5):1482-1487.

12. $\mathrm{Cu} \mathrm{Y}$, Booth CJ, Saltzman WM. In vivo distribution of surface-modified PLGA nanoparticles following intravaginal delivery. J Control Release. 2011;156(2):258-264.

13. Kieweg SL, Geonnotti AR, Katz DF. Gravity-induced coating flows of vaginal gel formulations: in vitro experimental analysis. J Pharm Sci. 2004;93(12):2941-2952.

14. Kieweg SL, Katz DF. Squeezing flows of vaginal gel formulations relevant to microbicide drug delivery. J. Biomech Eng. 2006;128(4): 540-553.

15. Mourtas S, Fotopoulou S, Duraj S, Sfika V, Tsakiroglou C, Antimisiaris SG. Liposomal drugs dispersed in hydrogels: effect of liposome, drug and gel properties on drug release kinetics. Colloid Surface B. 2007;55(2):212-221.

16. Justin-Temu M, Damian F, Kinget R, Van Den Mooter G. Intravaginal gels as drug delivery systems. $J$ Womens Health (Larchmt). 2004;13(7): 834-844.

17. Pavelić Ž, Škalko-Basnet N, Schubert R. Liposomal gels for vaginal drug delivery. Int J Pharm. 2001;219(1):139-149.

18. Lin HR, Sung KC. Carbopol/pluronic phase change solutions for ophthalmic drug delivery. J Control Release. 2000;69(3):379-388.

19. Lai SK, Wang YY, Hanes J. Mucus-penetrating nanoparticles for drug and gene delivery to mucosal tissues. Adv Drug Deliv Rev. 2009; 61(2):158-171.
20. Ensign LM, Cone R, Hanes J. Oral drug delivery with polymeric nanoparticles: the gastrointestinal mucus barriers. Adv Drug Deliv Rev. 2012;64(6):557-570.

21. Buttini F, Colombo P, Rossi A, Sonvico F, Colombo G. Particles and powders: tools of innovation for non-invasive drug administration. J Control Release. 2012;161(2):693-702.

22. Calvo P, Remunan-Lopez C, Vila-Jato JL, Alonso MJ. Novel hydrophilic chitosanepolyethylene oxide nanoparticles as protein carriers. J Appl Polym Sci. 1997;63(1):125-132.

23. Kuhn SJ, Hallahan DE, Giorgio TD. Characterization of superparamagnetic nanoparticle interactions with extracellular matrix in an in vitro system. Ann Biomed Eng. 2006;34(1):51-58.

24. Kirch J, Schneider A, Abou B, et al. Optical tweezers reveal relationship between microstructure and nanoparticle penetration of pulmonary mucus. Proc Natl Acad Sci U S A. 2012;109(45):18355-18360.

25. Rango Rao KV, Buri P. A novel in situ method to test polymers and coated microparticles for bioadhesion. Int J Pharm. 1989;52(3):265-270.

26. Goldbach P, Brochart H, Stamm A. Spray-drying of liposomes for a pulmonary administration. I. Chemical stability of phospholipids. Drug Dev Ind Pharm. 1993;19(19):2611-2622.

27. Mortazavi SA, Smart JD. An investigation into the role of water movement and mucus gel dehydration in mucoadhesion. $J$ Control Release. 1993;25(3):197-203.

28. Nordgård CT, Draget KI. Oligosaccharides as modulators of rheology in complex mucous systems. Biomacromolecules. 2011;12(8):3084-3090.

29. Nordgård CT, Nonstad U, Olderøy MØ, Espevik T, Draget KI Alterations in mucus barrier function and matrix structure induced by guluronate oligomers. Biomacromolecules. 2014;15(6):2294-2300.

30. Sosnik A, das Neves J, Sarmento B. Mucoadhesive polymers in the design of nano-drug delivery systems for administration by non-parenteral routes: a review. Prog Polym Sci. 2014;39(12):2030-2075.

31. Owen DH, Peters JJ, Katz DF. Rheological properties of contraceptive gels. Contraception. 2000;62(6):321-326.

32. Mortazavi SA. Investigation of various parameters influencing the duration of mucoadhesion of some polymer containing discs. DARU-J Pharm Sci. 2002;10(3):98-104.

33. Liu Q, Wang Y. Development of an ex vivo method for evaluation of precorneal residence of topical ophthalmic formulations. AAPS Pharm Sci Tech. 2009;10(3):796-805.

34. Galindo-Rodriguez SA, Allemann E, Fessi H, Doelker E. Polymeric nanoparticles for oral delivery of drugs and vaccines: a critical evaluation of in vivo studies. Crit Rev Ther Drug Carrier Syst. 2005; 22(5):419-464. 


\section{Supplementary materials}
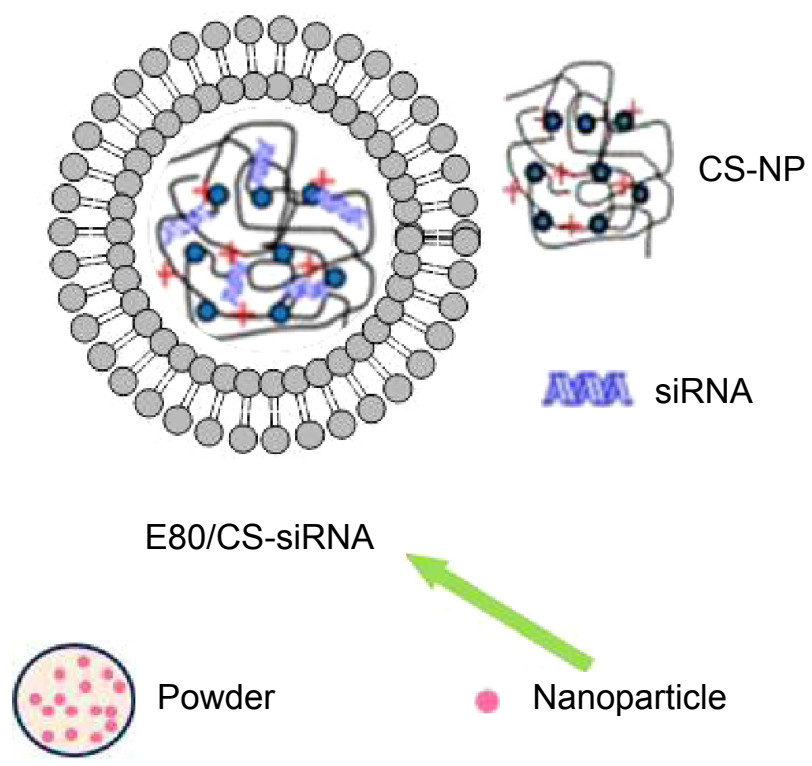

Figure SI The schematic diagram of the powdered siRNA delivery system.

Notes: The CS-siRNA was coated by an E80 lipid to form E80/CS-siRNA nanoparticle. The nanoparticles were then loaded into powders. Abbreviations: CS, chitosan; E80, Lipoid E80; NP, nanoparticle; siRNA, small interfering RNA.
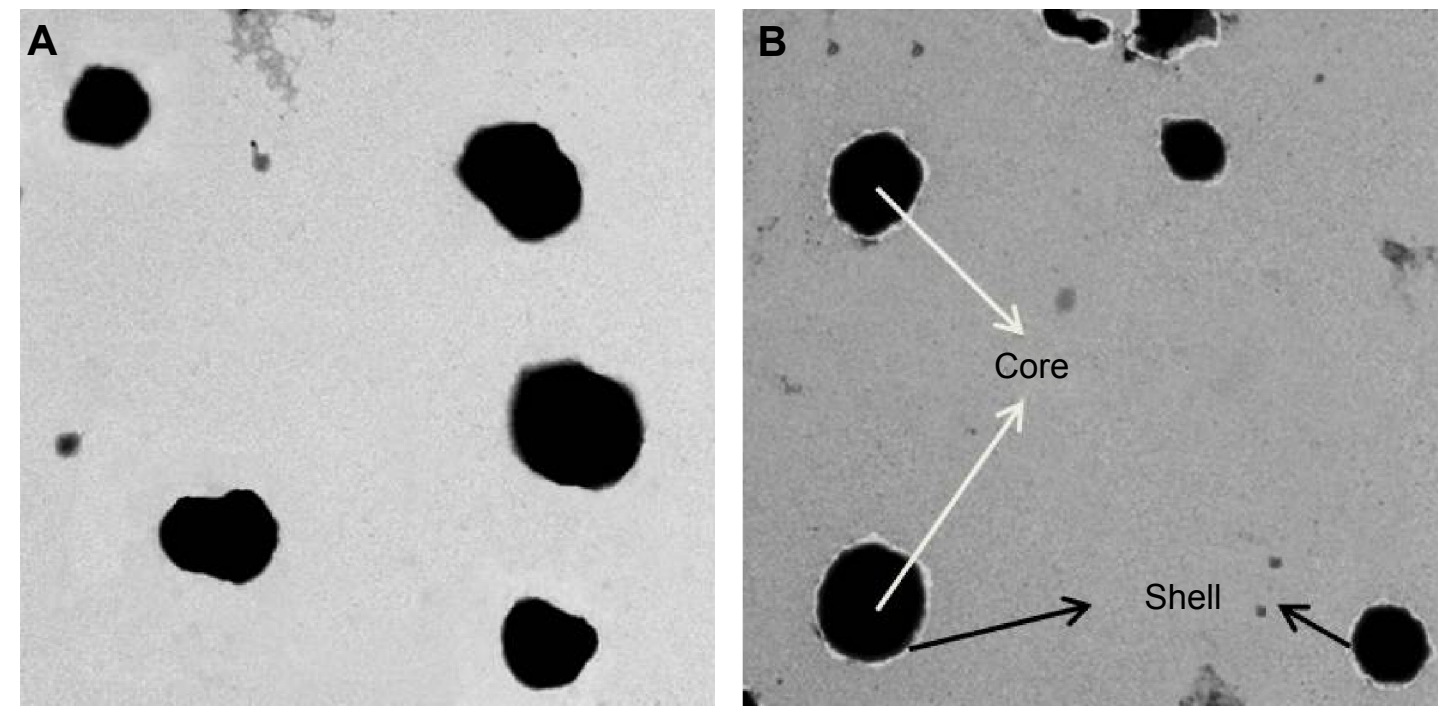

Figure S2 Transmission electron micrographs.

Notes: Micrographs of (A) CS-NPs and (B) E80/CS-NPs. Lipid shell can be observed on the surface of E80/CS-NP. The white arrows indicate the core of the NPs and the black arrows indicate the shell of the NPs.

Abbreviations: CS, chitosan; E80, Lipoid E80; NP, nanoparticle.

International Journal of Nanomedicine

\section{Publish your work in this journal}

The International Journal of Nanomedicine is an international, peerreviewed journal focusing on the application of nanotechnology in diagnostics, therapeutics, and drug delivery systems throughout the biomedical field. This journal is indexed on PubMed Central, MedLine, CAS, SciSearch ${ }^{\circledR}$, Current Contents $® /$ Clinical Medicine,

\section{Dovepress}

Journal Citation Reports/Science Edition, EMBase, Scopus and the Elsevier Bibliographic databases. The manuscript management system is completely online and includes a very quick and fair peer-review system, which is all easy to use. Visit http://www.dovepress.com/ testimonials.php to read real quotes from published authors. 